\title{
Meta-Analysis Orginal Scientific Papers in the Field of Swimming and Water polo Published in Sport Mont from 2003 to 2018
}

\author{
Marina Vukotic ${ }^{1}$ \\ 'University of Montenegro, Faculty for Sport and Physical Education, Niksic, Montenegro
}

\begin{abstract}
The main purpose of this research was to determine one meta analyses of published scientific papers in the field of swimming and water polo from Sport Mont from 2003 to 2018. In the above mentioned magazine the researches from different multidisciplinary and monodisciplinary fields were published. In this research, meta analysis were conducted from 15 original journals in the field of swimming and water polo. From the review of all original public papers it is evident that these are transversal researches and the aim is to research one observation treatment on different age groups of respondents. The scientific researches informs us about empirical foundings, new theories and theoretical perspectives as well as about methodological and technological developments. From the review of all published original scientific papers that are analysed it can be seen that these are scientific papers in the fields of swimming and water polo and they guide future researchers to increase the efficiency of the training process in above mentioned fields, as well as factors for observing anthropologic characteristics, motor and functional abilities.
\end{abstract}

Key words: Meta-Analysis, Sport Mont, Swimming, Water polo

\section{Uvod}

"Sport Mont" je časopis koji se sastoji od originalnih recenziranih naučnih članaka i interdisciplinarnih prikaza istraživanja iz oblasti sportske nauke, čiji su autori naučnici iz cijelog svijeta. Početak izlaženja publikacije bio je za uredništvo veoma težak, ali iz godine u godinu situacija se mijenjala, radovi koji su objavljivani bili su sve kvalitetniji, pa se može reći da je časopis "Sport Mont" dospio do visokog nivoa u svijetu nauke. Svrha časopisa je promocija nauke i istraživanja, sa posebnom pažnjom posvećenom sportskoj nauci širom Crne Gore i izvan nje (Vukotić, 2018). Ova meta analiza daje pregled objavljenih orginalnih naučnih radova iz oblasti plivanja i vaterpola u časpisu “Sport Mont” od 2003 do 2018. godine.

Za postizanje tehničkog i taktičkog kvaliteta u vaterpolu, potrebne su specifične morfološke karakteristike i motoričke spoosbnosti igrača, jer one određuju biomehaničke zakonitosti pokreta i kretnji. Razvojem vaterpolo igre postavljaju se igraču složeniji zahtjevi u pogledu pripreme. Znatan dio tih zahtjeva vezan je i za morfološke karakteristike, o čemu treba voditi računa još u periodu selekcije Plivanje je sposobnost čovjeka da se održava na površini vode i da se kreće po njoj (Trivun, 2008). Plivanje je cikličan monostrukturalni sport, prema obliku i načinu izvođenja dominiraju veoma jednostavni pokreti koji su stalno isti i koji se naizmenično ponavljaju u toku plivanja. Međutim dejstvo pokreta u toku plivanja i pored jednostavne forme veoma je složeno jer da bi pokreti delovali na kretanje tijela plivača, i da bi bili efikasni moraju imati kako prostornu tako i vremensku strukturu (Solaković, 2008). Svaki pokret je jedna kompleksna i složena kinetička cjelina za sebe koja podrazumijeva naizmeničnu i harmoničnu povezanost $\mathrm{u}$ jedan odgovarajući usklađen ritam. Plivanje postavlja specifične zahtijeve sportistma. Ti zahtijevi su uslovljeni: karakterom i trajanjem dinamičkih napora u procesu takmičarske aktivnosti. Za postizanje visokih rezultata na različitim stazama, od

\section{Correspondence:}

\section{Montenegro M.Vukotić}

Sport University of Montenegro, Faculty for Sport and Physical Education, Narodne omladine bb, 81400 Niksic, Montenegro E-mail: marinavuk@ac.me 
velikog je značaja sposobnost plivača da razvije maksimalnu brzinsku i eksplozivnu snagu i izdržljivost u snazi. Pomenuti oblici manifestovanja snage igraju različitu ulogu u omogućavanju visokih rezultata. Pošto se izvodi u specifičnoj sredini, vodi, koja poseduje određena fizička svojstva, koja imaju različit uticaj na organizam kao i na kretanje tela, to doprinosi kompleksnosti ove kretne aktivnosti (Trivun, 2009). Trening je jedna od najznačajnijih faza u pripremi vrhunskih plivača za takmičenja i postizanje adekvatnog ili željenog rezultata. Sportski trening je kompleksan pedagoški proces, koji se konkretizuje u organizovanom vježbanju radu, koje se ponavlja sa takvim opterećenjem da aktivira fiziološke procese superkompezacije i adaptacije organizma (Bjelica, 2006). Time se postiže poboljšanje fizičkih, psihičkih, intelektualnih, tehničkih i taktičkih kvaliteta sportiste, koji se manifestuju u postizanju takmičarskih rezultata (Bjelica, 2011). U svrhu optimalizacije treninga važno je imati uvid u aktuelno stanje relevantnih sposobnosti, osobina i znanja sportista kao i uvid u specifične zahtjeve pojedinog sporta ili sportske discipline (Bjelica, 2013). U jednačini specifikacije svakog sporta, pa i svake specifične funkcije kod sportista, antropološka dimenzija predstavlja važan faktor (Bjelica, 2005).

Osnovni cilj ovog istraživanja je bio da se utvrdi meta analiza objavljenih orginalnih naučnih radova iz oblasti plivanja i vaterpola u časopisu "Sport Mont" od 2003 do 2018. godine.

\section{Metod}

Meta analiza je metoda koja kvalitativno i kvantitativno sistematizuje objavljene radove na određenu temu, $\mathrm{u}$ ovom slučaju su to objavljen orginalni naučni radovi iz oblasti plivanja i vaterpola u časopisu "Sport Mont" od 2003 do 2018. godine. U pomenutom časopisu objavljeni su radovi iz različitih multidisciplinarnih i monodisciplinarnih oblasti. U ovoj studiji je sprovedena meta analiza 15 orginalnih naučnih radova, i to: 13 orginalnih naučnih radova iz oblasti plivanja i 2 orginalna naučna rada iz oblasti vaterpola. Iz pregleda objavljenih orginalnih radova vidi se da je riječ o transverzalnim istraživanjima, sa ciljem da se istraživanja odnose na jedan tretman posmatranja na različitim uzrasnim grupama ispitanika, a sa druge strane studije izvještavaju o empirijskim nalazima, matematičkim i računskim modelima, novim teorijama i teorijskim perspektivama, kao i o metodološkom i tehnološkom razvoju. Riječ je o naučnim radovima iz oblasti plivanja i vaterpola koje pružaju budućim istraživačima smjernice do povećane efikasnosti trenažnog procesa iz pomenutih oblasti, kao i dosta faktora za posmatranje antrpoloških karaketristika, motoričkih i funkcionalnih sposobnosti. Takođe treba naglasiti da je ova meta analiza radova sprovedena u skladu sa principima „Prioritetne stavke izvještaja za sistemeske preglede i meta analize (PRISMA)” (Moher i sar., 2009).

\section{Rezultati}

$\mathrm{Na}$ osnovu detaljne meta analize, utvrđeno je da broj elemenata koji utiču na brzinu plivanja zavisi od dionice koja se pliva. Ono što se sa sigurnošću može reći jeste to da je osnovni faktor koji generalno utiče na brzinu plivanja, položaj tijela u vodi. Međutim dejstvo pokreta u toku plivanja i pored jednostavne forme veoma je složeno jer da bi pokreti delovali

Tabela 1. Studije koje su analizirale objavljene orginalne radove iz oblasti plivanja

\begin{tabular}{|c|c|c|c|c|}
\hline Autor & Cilj istraživanja & Uzorak/ varijable & $\begin{array}{l}\text { Statist } \\
\text { Analiza }\end{array}$ & Rezultati \\
\hline $\begin{array}{l}\text { Čakareska, i } \\
\text { Simeva, } \\
(2008)\end{array}$ & $\begin{array}{l}\text { Utvrditi razlike kvalitetnijh } \\
\text { i manje kvalitetnijih plivača }\end{array}$ & $\begin{array}{l}90 \text { ispitanika, muškog pola / } \\
10 \text { varijabli iz flesibilnosti i } 2 \\
\text { varijable iz plivanja }\end{array}$ & $\begin{array}{l}\text { Rregresiona } \\
\text { analiza }\end{array}$ & $\begin{array}{l}\text { Utvrđene su statistički značajne } \\
\text { razlike između aktivnih i manje } \\
\text { aktivnih plivača, na nivou } p<.05\end{array}$ \\
\hline $\begin{array}{l}\text { Dimitrić, i } \\
\text { Obradović, } \\
\text { (2008) }\end{array}$ & $\begin{array}{l}\text { Utvrditi razlike plivanja } \\
\text { i hidrodinamičnosti kao } \\
\text { parameri uspješnosti }\end{array}$ & $\begin{array}{l}63 \text { ispitanika, mukog pola } \\
/ 15 \text { varijabli iz oblasti } \\
\text { motorike i morfologije }\end{array}$ & $\begin{array}{l}\text { Regresiona } \\
\text { analiza }\end{array}$ & $\begin{array}{l}\text { Utvrđene su statistički značajne } \\
\text { razlike u vaijablama između } \\
\text { motorike antropometrije, na nivou } \\
p<.05\end{array}$ \\
\hline $\begin{array}{l}\text { Trivun, } \\
(2008)\end{array}$ & $\begin{array}{l}\text { Utvrditi razlike indeksa } \\
\text { tjelesne mase na stilizovane } \\
\text { oblike kretanja tehnike } \\
\text { plivanja }\end{array}$ & $\begin{array}{l}128 \text { ispitanika muškog } \\
\text { pola / indeks tjelesne mase } \\
\text { plivanje na } 50 \text { i } 100 \mathrm{~m}\end{array}$ & $\begin{array}{l}\text { Regresiona } \\
\text { analiza }\end{array}$ & $\begin{array}{l}\text { Utvrđene su značajne razlike u } \\
\text { vaijablama indeksa tjelesne mase } \\
\text { na stilizovane oblike kretanja. na } \\
\text { nivou } p<.05\end{array}$ \\
\hline $\begin{array}{l}\text { Trivun i } \\
\text { Vuković } \\
(2008)\end{array}$ & $\begin{array}{l}\text { Utvrditi razlike između } \\
\text { djevojčica prilikom } \\
\text { procjene bazično motoričke } \\
\text { sposobnosti i plivanja }\end{array}$ & $\begin{array}{l}70 \text { ispitanika ženskog pola, / } \\
6 \text { testova iz motorike i jedan } \\
\text { test iz plivanja }\end{array}$ & $\begin{array}{l}\text { Kanonička } \\
\text { analiza }\end{array}$ & $\begin{array}{l}\text { Utvrđene su statistički značajne } \\
\text { razlike u varijablama kod djevojčica, } \\
\text { na nivou } p<.05\end{array}$ \\
\hline $\begin{array}{l}\text { Sokolović, } \\
\text { (2008) }\end{array}$ & $\begin{array}{l}\text { Utvrditi razlike kod } \\
\text { studenata plivačku } \\
\text { efikasnost i plivački kvalitet }\end{array}$ & $\begin{array}{l}35 \text { ispitanika muškog } \\
\text { pola / } 3 \text { varijable plivačke } \\
\text { efikasnosti i } 3 \text { varijable } \\
\text { plivačkog kavlaiteta }\end{array}$ & ANOVA & $\begin{array}{l}\text { Utvrđene su statistički značajne } \\
\text { razlike u vaijablama između } \\
\text { plivačkog kvaliteta i egikasnosti } \\
\text { plivanja, na nivou p<.05 }\end{array}$ \\
\hline $\begin{array}{l}\text { Dimitrić, } \\
(2010)\end{array}$ & $\begin{array}{l}\text { Utvrditi razlike } \\
\text { pojedinačnih doprinosa } \\
\text { rada ruku i nogu na ukupnu } \\
\text { brzinu plivanja }\end{array}$ & $\begin{array}{l}17 \text { ispitanika muškog pola } \\
\text { /dva specifična motorička } \\
\text { testa u vodi }\end{array}$ & $\begin{array}{l}\text { Regresiona } \\
\text { analiza }\end{array}$ & $\begin{array}{l}\text { Utvređene su statistički značajne } \\
\text { razlike u vaijablama između } \\
\text { specifičnih motoričkih testova, na } \\
\text { nivou } p<.05\end{array}$ \\
\hline $\begin{array}{l}\text { Dimitrić, } \\
\text { i sar. (2010) }\end{array}$ & $\begin{array}{l}\text { Utvrditi razlike } \\
\text { antropometrijskih varijabli } \\
\text { na brzinu plivanja }\end{array}$ & $\begin{array}{l}30 \text { ispitanika muškog pola / } \\
4 \text { varijable iz antropometrije } \\
\text { i plivanje na } 50 \mathrm{~m} \text {. }\end{array}$ & $\begin{array}{l}\text { Regresiona } \\
\text { analiza }\end{array}$ & $\begin{array}{l}\text { Utvrđene su statistički značajne } \\
\text { razlike u vaijablama između } \\
\text { plivača, na nivou } \mathrm{p}<.05\end{array}$ \\
\hline
\end{tabular}


(continued from previous page)

\begin{tabular}{|c|c|c|c|c|}
\hline Autor & Cilj istraživanja & Uzorak/ varijable & $\begin{array}{c}\text { Statist } \\
\text { Analiza }\end{array}$ & Rezultati \\
\hline $\begin{array}{c}\text { Dimitrić, } \\
\text { i sar. (2010) }\end{array}$ & $\begin{array}{l}\text { Utvrditi razlike elemenata } \\
\text { koji utiču na procjenu } \\
\text { brzine plivanja }\end{array}$ & $\begin{array}{l}66 \text { ispitanika muškog pola / } \\
7 \text { varijabli za provjenu brzine } \\
\text { plivanja }\end{array}$ & $\begin{array}{l}\text { Regresiona } \\
\text { analiza }\end{array}$ & $\begin{array}{l}\text { Utvrđene su statistički značajne } \\
\text { razlike u vaijablama između } \\
\text { testova za procjenu brzine plivanja, } \\
\text { na nivou } p<.05\end{array}$ \\
\hline $\begin{array}{l}\text { Trivun } \\
\text { i sar. (2011) }\end{array}$ & $\begin{array}{l}\text { Utvrditi razlike } \\
\text { antropometrijskih varijabli } \\
\text { na brzinu plivanja }\end{array}$ & $\begin{array}{l}23 \text { ispitanika muškog pola / } \\
11 \text { testova iz antropometrije } \\
\text { i test na } 50 \mathrm{~m}\end{array}$ & $\begin{array}{l}\text { Regresiona } \\
\text { analiza }\end{array}$ & $\begin{array}{l}\text { Utvrđene su statistički značajne } \\
\text { razlike } u \text { vaijablama između } \\
\text { testova za procjenu brzine plivanja, } \\
\text { na nivou } p<.05\end{array}$ \\
\hline $\begin{array}{l}\text { Tošić i sar. } \\
\text { (2011) }\end{array}$ & $\begin{array}{l}\text { Utvrditi razlike } \\
\text { atropomeriskih varijabli i } \\
\text { procjenu brzine plivanja }\end{array}$ & $\begin{array}{l}50 \text { ispitanika ženskog pola } \\
\text { / } 3 \text { testa iz antropometrije, } \\
12 \text { testova iz feleksibilnosti i } \\
\text { plivanje na } 50 \mathrm{~m}\end{array}$ & $\begin{array}{l}\text { Regresiona } \\
\text { analiza }\end{array}$ & $\begin{array}{l}\text { Utvrđene su statistički značajne } \\
\text { razlike u vaijablama između } \\
\text { testova za procjenu brzine plivanja, } \\
\text { na nivou } p<.05\end{array}$ \\
\hline $\begin{array}{l}\text { Beganović, } \\
\text { (2011) }\end{array}$ & $\begin{array}{l}\text { Utvrditi razlike tehničkih } \\
\text { sposobnosti na uspješnost } \\
\text { izvođenja mješovitog } \\
\text { plivanja }\end{array}$ & $\begin{array}{l}72 \text { ispitanika muškog } \\
\text { pola/12 antropometrijskih, } 4 \\
\text { funkcionalne i } 8 \text { varijabli za } \\
\text { procjenu plivanja }\end{array}$ & $\begin{array}{l}\text { Kanonička } \\
\text { analiza }\end{array}$ & $\begin{array}{l}\text { Utvrđene su statistički značajne } \\
\text { razlike u vaijablama između } \\
\text { ispitanika, na nivou } p<.05\end{array}$ \\
\hline $\begin{array}{l}\text { Kocić, i sar } \\
\quad(2012)\end{array}$ & $\begin{array}{l}\text { Utvrditi razlike između } \\
\text { grupa studenata } \\
\text { obuhvaćenih različitim } \\
\text { trenažnim procesom }\end{array}$ & $\begin{array}{l}103 \text { isptanika / dvije varijable } \\
\text { za procjenu plivanja }\end{array}$ & ANOVA & $\begin{array}{l}\text { Utvrđene su statistički značajne } \\
\text { razlike u varijablama kod studenata, } \\
\text { na nivou } p<.05\end{array}$ \\
\hline $\begin{array}{l}\text { Gllareva, i sar. } \\
\qquad(2014)\end{array}$ & $\begin{array}{l}\text { Utvrditi razlike između } \\
\text { grupa studenata } \\
\text { obuhvaćenih različitim } \\
\text { trenažnim procesom }\end{array}$ & $\begin{array}{l}100 \text { ispitanika muškog pola/ } \\
\text { dvije varijable iz plivanja }\end{array}$ & ANOVA & $\begin{array}{l}\text { Utvrđene su statistički značajne } \\
\text { razlike u vaijablama između } \\
\text { ispitanika, na nivou } p<.05\end{array}$ \\
\hline
\end{tabular}

na kretanje plivačevog tijela, i da bi bili efikasni moraju imati kako prostornu tako i vremensku strukturu. Svaki pokret je jedna kompleksna i složena kinetička cjelina za sebe koja podrazumijeva naizmjeničnu i harmoničnu povezanost $\mathrm{u}$ jedan odgovarajući usklađen ritam, utvrđeno je sa druge strane. Parametri koji prate biomehaničke pokrete i kretanja u vodi su vezani za antropometrijske karakeristike, motoričke i funkcionalne sposobnosti (Čakareska, i Simeva, 2008; Dimitrić, i Obardović, 2008; Trivun, 2008; Trivun i Vuković, 2008; Sokolović, 2008; Dimitrić, Obradović, Krsmanović, Šolaja, i Grujić, 2010; Dimitrić, Obradović, Krsmanović, i Šolaja, 2010; Bego- vić, 2011; Trivun, Vuković, i Budimlić, 2011; Tošić, Mekić, i Aleksić, 2011; Kocić, Tošić, Aleksić, i Toskić, 2012; Gllareva, Halilaj, \& Koca, 2014).

$\mathrm{Na}$ osnovu detaljne meta analize može se vidjeti da je riječ o vrlo malom broju orginalnih naučnih radova u časopisu "Sport Mont" kada je u pitanju oblast vaterpola. Za postizanje tehničkog i taktičkog kvaliteta u vaterpolu, potrebne su specifične morfološke karakteristike igrača, jer one određuju biomehaničke zakonitosti pokreta i kretnji (Popovski, Aleksandrović, i Madić, 2005; Aleksandrović, Popovski i Madić, 2005)

Tabela 2. Studije koje su analizirale objavljene orginalne radove iz oblasti vaterpola

\begin{tabular}{cllll}
\hline Autor & \multicolumn{1}{c}{ Cilj istraživanja } & \multicolumn{1}{c}{ Uzorak/ varijable } & $\begin{array}{c}\text { Statist. } \\
\text { Analiza }\end{array}$ & \multicolumn{1}{c}{ Rezultati } \\
\hline $\begin{array}{c}\text { Popovski i asr. } \\
\text { (2005) }\end{array}$ & $\begin{array}{l}\text { Utvrditi razlike morfoloških } \\
\text { karakteristika i motoričkih } \\
\text { sposobnosti u periodu rane } \\
\text { selekcije vaterpolista. }\end{array}$ & $\begin{array}{l}90 \text { ipitanika, muškog pola / } \\
12 \text { antopometrisjkih varijabli }\end{array}$ & $\begin{array}{l}\text { Kanonička } \\
\text { analiza }\end{array}$ & $\begin{array}{l}\text { Utvrđene su statistički značajne } \\
\text { razlike u vaijablama između } \\
\text { ispitanika plivača, na nivou p<.05 }\end{array}$ \\
$\begin{array}{clll}\text { Aleksandrović i i } \\
\text { sar. (2005) }\end{array}$ & $\begin{array}{l}\text { Utvrditi razlike povezanosti } \\
\text { motoričkih sposobnosti } \\
\text { vaterpolista na suvom }\end{array}$ & $\begin{array}{l}\text { 12 varijabli iz motorike i } \\
\text { 6 testova iz situacionog } \\
\text { plivanja }\end{array}$ & $\begin{array}{l}\text { Kanonička } \\
\text { analiza }\end{array}$ & $\begin{array}{l}\text { Utvrđene su statistički značajne } \\
\text { razlike u vaijablama između } \\
\text { motorike i situacionog plivanja, na } \\
\text { nivou p<.05 }\end{array}$ \\
\hline
\end{tabular}

\section{Diskusija}

Na osnovu detaljne meta analize ove studije mogu se izvoditi zaključci sa više aspekata. Sa aspekta selekcije plivača može zaključiti da se ona odvijata na nekoliko nivoa i u nekoliko pravaca sa ciljem da se izdvoje plivači sa nizom karakteristika i specifično motoričkih sposobnosti koje bi doprinele efikasnijem plivanju. Sa aspekta primjenjivosti konkretnih rezultata, može se zaključiti da je poželjno u okviru pozitivne selekci- je birati plivače koji u najranijem dobu nagovještavaju mogućnost da budu visoki. Sa takvim plivačima treba strpljivo i dugo raditi, na poboljšanju drugih karakteristika koje bi sa tjelesnom visinom i drugim longitudinalnim karakteristikama došle do izražaja u plivanju, kroz postizanje rezultata velikih vrijednosti (Trivun, 2008; Dimitrić, Obradović, Krsmanović, Šolaja, i Grujić, 2010; Dimitrić, Obradović, Krsmanović, i Šolaja, 2010; Begović, 2011; Trivun, Vuković, i Budimlić, 2011; 
Tošić, Mekić, i Aleksić, 2011). Poslednjih godina i konstantnih promjena u plivanju, još uvek se mogu odrediti stalno prisutne teme a to su: neprestano poboljšanje tehnike plivanja poboljšanje metoda treninga, korišćenje znanja i uloga dinamike ljudskog tela. Postoje očigledne anatomske razlike koje određuju do koje mjere čovjek može primijeniti određene mehanizme u plivanju. S obzirom da je fleksibilnost jedan od tih mehanizama došlo se do pozitivnih razlika među plivačima različitog kvaliteta, a to znači da bi model selekcije trebalo da se odvoji kod plivača (Čakareska, i Simeva, 2008; Kocić, Tošić, Aleksić, i Toskić, 2012; Gllareva, Halilaj, \& Koca, 2014). Sa druge strane, postojeće relacije morfoloških karakteristika i situaciono-plivačkih sposobnosti vaterpolista u ranim fazama selekcije mogu poslužiti poboljšanju selekcije i trenažnog tretmana (Popovski, Aleksandrović, i Madić, 2005).

Da podsjetimo, časopis Sport Mont objavljuje originalne recenzirane naučne članake i interdisciplinarne prikaze istraživanja iz oblasti sportskih nauka. Svrha časopisa je promocija nauke i istraživanja, sa posebnom pažnjom posvećenom sportskoj nauci širom Crne Gore i izvan nje. Meta analiza daje pregled objavljenih orginalnih naučnih radova iz oblasti plivanja i vaterpola u časpisu "Sport Mont" od 2003 do 2018. godini. Ovaj pregled pokazuje diskriminativnu analizu prikupljenih studija i obrađenih podataka. $\mathrm{Na}$ osnovu dobijenih rezultata iz orginalnih objavljenih naučnih radova može se registrovati određeno stanje sportiste, i napraviti upoređenje sa nekim prethodno utvrđenim kriterijumom. Naime, dobijeni rezultati mogu biti usmjereni u pravcu inoviranja planova $\mathrm{i}$ programa rada, te prilagođavanju istih potrebama dotične populacije. Pored dijagnostikovanja, planiranja i programiranja trenažnog procesa, rezultati se mogu primijeniti i u svrhu individualnog praćenja sportista, i unošenja korekcije u metode obučavanja, utvrđivanja i unapređivanja razlika sposobnosti kod sportista različitog sporskog usmjerenja.

\section{Acknowledgements}

There are no acknowledgements.

\section{Conflict of Interest}

The authors declare that there are no conflicts of interest.

Received: 14 August 2018| Accepted: 19 September 2018| Published: 29 October 2018

\section{References}

Aleksandrović, M., Popovski, D., i Madić, D. (2005). Povezanost bazično-motoričkih i plivačko situacionih sposobnosti selekcionisanih vaterpolista. Sport Mont, 3(6-7), 313-9.

Beganović, E. (2011). The impact of technical ability to swimming performance of the mixed swimming at $100 \mathrm{~m}$ in college fasto. Sport Mont, 9(28-29-30), 201-10.

Bjelica, D. (2005). Sistematizacija sportskih disciplina i sportski trening. Podgorica: Crnogorska sportska akademija.

Bjelica, D. (2006). Sportski trening. Podgorica: Crnogorska sportska akademija.

Bjelica, D. (2013). Teorija sportskog treninga. Podgorica: Univerzitet Crne Gore.

Bjelica, D., i Fratrić, F. (2011). Sportski trening: teorija, metodika i dijagnostika. Nikšić: Fakultet za sport i fizičko vaspitanje.

Cakareska, L., \& Simeva, V. (2008). Relations among some tests for evaluation of flexibility and swimming results at swimmers with different qualities in 50 and 100 meters butterfly. Sport Mont, 6(15-16-17), 778-3.

Dimitrić, G., \& Obradović, B. (2008). Hydrodinamics and swimming tehnique as parameters for successfull swimming at the age 10-12. Sport Mont, 6(15-16-17), 595-600.

Dimitrić, G., Obradović, B., i Vasić, G. (2010). Parametri koji utiču na brzinu plivanja na dionici $100 \mathrm{~m}$ kraul tehnikom kod studenata fakulteta sporta i fizičkog vaspitanja. Sport Mont, 8(23-24), 414-7.

Dimitrić, G., Obradović, B., Krsmanović, T., i Šolaja, M. (2010). Relacije između antropometrijskih karakteristika i rezultata plivanja na $50 \mathrm{~m}$ kraul tehnikom plivača uzrasta 13-14 godinA. Sport Mont, 8(23-24), 311-4.

Dimitrić, G., Obradović, B., Krsmanović, T., Solaja, M., \& Grujić, I. (2010). Pojedinačan uticaj rada ruku i nogu na brzinu plivanja 50 metara kraul kod dečaka uzrasta 15 i 16 godina. Sport Mont, 8(23-24), 259-2.

Gllareva, I., Halilaj, B., \& Koca, A. (2014). Analyze of results of the kosovo swimmers along eight year period, breaststroke technique at disciplines 50 and 200 meters. Sport Mont, X12(40-41-42), 28-2.

Kocić, J., Tošić, S., Aleksić, D., \& Toskić, D. (2012). The influence of recreative synchronized swimming on music and intellectual factors and personal characteristics. Sport Mont, 10(34-35-36), 508-20.

Popovski, D., Aleksandrović, M., i Madić, D. (2005). Relacije morfoloških karakteristika i plivačko - situacionih sposobnosti selekcionisanih vaterpolista. Sport Mont, (6-7), 19-24.

Solaković, E. (2008). Transformacioni procesi plivačke tehnike i plivačkih performansi pod utjecajem kondenzovanog nastavnog procesa. Sport Mont, 6 (15-16-17), 496-500.

Tošić, S., Mekić, B., \& Aleksić, D. (2011). Effect of flexibility on the results of dolphin swimming technique. Sport Mont, 9(31-32-33), 295-301.

Trivun, M. (2008). The homogeneity of the results depending on the distances and swimming techniques. Sport Mont, 5(12-13-14), 216-24.

Trivun, M., \& Vuković, S. (2008). The effects of the teaching swimming process on students. Sport Mont, 6(15-16-17), 268-81.

Trivun, M., Vuković, S., \& Budimlić, J. (2011). The relations between anthropological dimensions and swimming the breast stroke. Sport Mont, 9(3132-33), 166-70.

Vukotić, M. (2018). Analysis of the Content of Published Articles in the Journal Sport Mont in 2006. Jaspe, 2(1), 31-39.

Vuković, S., \& Trivun, M. (2010). Anthropological students' status and the results' success in swimming. Sport Mont, 8(23-24), 301-10. 